OPEN ACCESS

Edited by:

Arian Te Pas,

Leiden University Medical Center,

Netherlands

Reviewed by:

Eric Giannoni,

Centre Hospitalier Universitaire

Vaudois, Switzerland

Gianluca Lista,

Ospedale dei Bambini Vittore Buzzi,

Italy

Bambini- "Vittore Buzzi"-ICP, Italy

Elizabeth Foglia,

University of Pennsylvania

School of Medicine, USA

${ }^{*}$ Correspondence:

Eugene M. Dempsey

g.dempsey@ucc.ie

Specialty section: This article was submitted to Neonatology,

a section of the journal

Frontiers in Pediatrics

Received: 22 January 2016 Accepted: 18 March 2016

Published: 31 March 2016

Citation:

Finn D, Boylan GB, Ryan CA and Dempsey EM (2016) Enhanced

Monitoring of the Preterm Infant

during Stabilization

in the Delivery Room.

Front. Pediatr. 4:30.

doi: 10.3389/fped.2016.00030

\section{Enhanced Monitoring of the Preterm Infant during Stabilization in the Delivery Room}

\author{
Daragh Finn ${ }^{1,2}$, Geraldine B. Boylan ${ }^{1,2}$, C. Anthony Ryan ${ }^{1,2}$ and Eugene M. Dempsey ${ }^{1,2 *}$ \\ ${ }^{1}$ Department of Paediatrics and Child Health, University College Cork, Cork, Ireland, ${ }^{2}$ Irish Centre for Fetal and Neonatal \\ Translational Research, University College Cork, Cork, Ireland
}

Monitoring of preterm infants in the delivery room (DR) remains limited. Current guidelines suggest that pulse oximetry should be available for all preterm infant deliveries, and that if intubated a colorimetric carbon dioxide detector should provide verification of correct endotracheal tube placement. These two methods of assessment represent the extent of objective monitoring of the newborn commonly performed in the DR. Monitoring non-invasive ventilation effectiveness (either by capnography or respiratory function monitoring) and cerebral oxygenation (near-infrared spectroscopy) is becoming more common within research settings. In this article, we will review the different modalities available for cardiorespiratory and neuromonitoring in the DR and assess the current evidence base on their feasibility, strengths, and limitations during preterm stabilization.

Keywords: preterm, newly born infant, monitoring, neuromonitoring, delivery-room, stabilization, resuscitation

\section{KEY POINTS}

Current ILCOR Guidelines recommend for all preterm infant deliveries:

- Pulse oximetry for $\mathrm{SpO}_{2}$ monitoring and titration of $\mathrm{O}_{2}$ therapy

- Pulse oximetry and consideration of ECG as an adjunct for heart rate monitoring

- $\mathrm{CO}_{2}$ detectors to verify correct endotracheal tube positioning

\section{INTRODUCTION}

In recent decades, we have witnessed a significant increase in the number of monitoring options for preterm infants in the neonatal intensive care unit (NICU) setting. Examples include cardiac (echocardiography and non-invasive cardiac output monitoring), respiratory (capnography and respiratory function monitoring), and neurological monitoring [electroencephalography (EEG) and near-infrared spectroscopy (NIRS)]. By contrast, over the same timeframe, monitoring of preterm infants in the delivery room (DR) has changed very little, other than the introduction of pulse oximetry approximately 10 years ago.

As adjuncts to clinical monitoring during initial preterm stabilization in the DR, the recent 2015 ILCOR recommendations advise the use of two objective assessment tools: (1) pulse oximetry (with or without ECG) to regulate oxygen delivery and (2) exhaled carbon dioxide $\left(\mathrm{CO}_{2}\right)$ detectors for confirmation of correct endotracheal (ET) tube placement (1). These two devices generate real-time accurate physiological data and, if recorded, chronicle changing observations over time. 
The information provided assists in clinical decision-making and has the potential to improve both short- and long-term outcomes for preterm infants.

The relative lack of monitoring options in the DR is both a reflection of the difficulties in acquiring the information and interpreting these data for decision-making in real-time. As Bradley and Field reflected, "not all that is measurable is of value, and not all that is of value can be measured" (2). Introducing new monitoring devices into clinical care remains challenging. Feasibility studies are initially required to assess whether new devices can be applied safely, useful information acquired, interpreted, and acted upon in the simulation environment. Human factors need to be considered and evaluated prior to introduction of new technology into the clinical environment. This may involve additional team training, possibly in the form of newborn resuscitation simulations, and it should be highlighted that new devices should not distract team members from complying with current resuscitation recommendations. Preterm adaptation represents a unique physiological time in life. Ideally, both shortand long-term benefits should be evaluated by randomized controlled trials prior to the introduction of a new device into routine clinical care.

This review will present an overview of current methods of preterm newborn monitoring in the DR, from simple clinical evaluation to the potential role of newer monitoring devices, including monitoring cerebral activity and cerebral oxygenation during the first minutes of life (Table 1).

\section{HISTORICAL CONTEXT: CLINICAL ASSESSMENT OF THE PRETERM INFANT AND THE APGAR SCORE}

Dr. Virginia Apgar, in 1953, was the first to describe newborn monitoring in the DR in a methodical manner. The Apgar score is the sum of values based on the newborn respiratory (respirations, skin color), cardiovascular [heart rate (HR), skin color], and neurological (muscle tone, reflex irritability) systems (3). With the exception of $\mathrm{HR}$, all of the variables are based on visual inspection of the infant and as such are somewhat subjective. Large cohort studies identified that 5-min Apgar scores of $<7$ were associated with increased risk of neonatal death and cerebral palsy in both term and preterm infants (4-6), indicating that early clinical assessments may be reliable and meaningful for newborn infants. On addressing the interrater variability of the score, Apgar reported that, "When two or more people decide independently, we find a range of one value above or below a decided score to be the widest variation" $(7,8)$. Currently, Apgar scores remain central to our interpretation of a newborn's condition at birth. They are routinely assigned to all infants in the immediate postnatal period and are usually collected as part of research trials both to assess baseline characteristics of study participants and in some cases as outcome measures. Newborn resuscitation guidelines advise initiating support during infants' transition based on the assessment of respirations, tone, and HR, which are all components of the Apgar score (9-11).

However, more recent studies have shown poor inter- and intrarater reliability with regard to Apgar score assignment, especially when the infant is preterm or ventilated $(12,13)$. The ability of the 5-min Apgar score to predict outcome seem less likely than previously thought. Singh et al. have shown that in very preterm infant delivery, there is no Apgar score cutoff below which "a burdensome outcome was assured or above which an unscathed outcome was likely." Five-minute Apgar score and HR values also displayed poor sensitivity and specificity for either survival or survival without disability (14). Manley and colleagues asked clinicians to predict the outcome of preterm infants ( $<26$ weeks gestation) based on their clinical appearance in the DR, at prespecified time points of $20 \mathrm{~s}, 2 \mathrm{~min}$, and $5 \mathrm{~min}$. This study was based on video recordings of the preterm infants, and monitors displaying $\mathrm{HR}$ and oxygen saturation $\left(\mathrm{SpO}_{2}\right)$ values were visible. Trainees and staff neonatologists predicted infant survival poorly at each time point. The authors concluded that neonatologists' "reliance on initial appearance and early response

TABLE 1 | Summary of monitoring devices.

\begin{tabular}{|c|c|c|c|c|c|}
\hline Variable & Monitor & $\begin{array}{l}\text { Data acquisition } \\
\text { feasible }\end{array}$ & $\begin{array}{l}\text { Normative values } \\
\text { established }^{\mathrm{a}}\end{array}$ & Comments & $\begin{array}{l}\text { Strength of } \\
\text { recommendation }\end{array}$ \\
\hline $\begin{array}{l}\mathrm{SpO}_{2} \\
\mathrm{HR}\end{array}$ & Pulse oximeter & + & + & Accurate but unable to detect hyperoxemia & Class I \\
\hline \multirow[t]{2}{*}{ Peripheral perfusion } & Echocardiography/NICOM & + & - & Not assessed in preterm infants & Class III \\
\hline & Perfusion index & + & + & Normative values highly variable in newborns & Class III \\
\hline ETT position & $\mathrm{CO}_{2}$ detector & + & $\mathrm{n} / \mathrm{a}$ & Reduces time to confirmation of correct placement & Class I \\
\hline & Capnography & + & - & $\begin{array}{l}\text { Reduces mask leak and obstruction } \\
\text { Further RCTs required }\end{array}$ & Class Ila \\
\hline & Respiratory function monitor & + & - & $\begin{array}{l}\text { Reduces mask leak and obstruction } \\
\text { Further RCTs required }\end{array}$ & Class Ila \\
\hline Cerebral oxygenation & NIRS & + & + & Advise as part of further RCTs & Class Ilb \\
\hline Cerebral activity & EEG & + & - & $\begin{array}{l}\text { Advise further feasibility trials and establishment of } \\
\text { normative reference values }\end{array}$ & Class III \\
\hline
\end{tabular}

aFor preterm infants, $<32$ weeks gestation in the immediate newborn period. 
to resuscitation in predicting survival for extremely premature infants is misplaced" (15).

Updated Apgar scoring systems have been proposed and allow for more appropriate descriptions of the condition of the preterm infant at birth. The Combined-Apgar score reports the infants' score in each of the five components of the Apgar score (specified Apgar score), and the interventions required to achieve this score (expanded Apgar score) $(16,17)$. This combined-Apgar score has been shown to be superior in predicting outcome in preterm infants when compared to the conventional-Apgar score (18). However, this updated scoring system has yet to be universally adopted and the relevance of conventional Apgar scores in preterm infants remains limited.

\section{OXYGEN SATURATION MONITORING}

Clinically, infants transition from blue (cyanotic) to pink (normal oxygen saturations) in color during uncomplicated newborn transition. O'Donnell and colleagues assessed clinical perceptions of newborn infant color in the DR (19). They found wide variation in observations and concluded that, "clinical assessment of a newborn infant's color may be unreliable." Assessment of arterial oxygen saturation by pulse oximetry is based on the Beer-Lambert law that relates the attenuation of light to the properties of the materials through which the light is traveling; and photoplethysmography, a non-invasive optical technique used to detect blood volume changes in the microvascular bed of the tissue (20). Aoyagi and Kishi, who realized that oxygenated hemoglobin absorbs more light at infrared wavelengths and deoxygenated hemoglobin absorbs more light at red wavelengths, developed arterial oxygen saturation monitoring by pulse oximetry in 1972. The changes during systole and diastole in the ratio of red and infrared light energy absorption are used to produce the pulse oxygen saturation (21).

The device was first commercialized in 1981, and the use of pulse oximetry for continuous oxygen monitoring in newborns was first described in 1986 (22). The clinical benefits of pulse oximetry were quickly recognized, and it has become the mainstay of non-invasive, continuous $\mathrm{SpO}_{2}$ monitoring in newborns (23). Oxygen saturation monitoring of preterm infants is now standard in the DR, and these values serve as a guide to stabilization (22, 23 ), and the titration of oxygen therapy in preterm newborn stabilization is now routine to achieve targeted saturations by $10 \mathrm{~min}$ of age $(24,25)$. Dawson and colleagues have published oxygen saturation percentile charts for the first $10 \mathrm{~min}$ of life (24). In their study of over 450 infants, they observed the $\mathrm{SpO}_{2}$ values of preterm infants increased at a slower pace than term infants. At $5 \mathrm{~min}$, the median (interquartile range) $\mathrm{SpO}_{2}$ was $86 \%$ (80-92) in preterm and $92 \%$ (83-96) in term infants. They have published three sets of percentile charts based on gestation $(>37,32-37$, and $<32$ weeks), which may guide neonatal teams in titrating oxygen therapy in the DR. However, these ranges were developed in a cohort of infants born when immediate cord clamping was frequently practiced following delivery. Smit and colleagues assessed over 100 term infants with delayed cord clamping and concluded that the Dawson curves are still relevant; however, they documented higher initial $\mathrm{SpO}_{2}$ values, lower HRs, and a slower increase over the first 3 min of life (26).

Pulse oximetry has gained widespread acceptance in neonatal care over the past three decades because of its reliability, ease of use, and lack of heat-related complications. The main physiological limitation of pulse oximetry is the inability to detect hyperoxemia in the higher $\mathrm{SpO}_{2}$ range (>90\%) because of the shape of the oxygen-hemoglobin dissociation curve. Thus, relatively small increases in $\mathrm{SpO}_{2}$ can be associated with a large increase in $\mathrm{PaO}_{2}$ (27-29). This is particularly important for preterm infants receiving supplemental oxygen because of their vulnerability to oxygen toxicity and oxidative stress (30). Despite this limitation, pulse oximetry is the gold standard for monitoring oxygen saturation during preterm infant stabilization, and it should be used following all preterm deliveries.

\section{HEART RATE MONITORING}

Monitoring HR helps to guide newborn transition and the need for intervention in the DR. Current recommendations advise that HR should be assessed clinically, and if positive pressure ventilation is commenced HR should be monitored by pulse oximetry, with the option of additional ECG monitoring (1).

Although clinical assessment of $H R$ by auscultation at the apex is more accurate than assessment by palpation of the umbilicus (31), all clinical assessments may misrepresent the actual HR. Kamlin et al. compared palpation and auscultation of HR to ECG determined HR in term newborns in the DR. They found that clinical assessments were inaccurate, and infant HR was underestimated when compared with ECG HRs (32). Hawkes et al. studied health-care professionals as they palpated a simulated pulsating umbilicus, listened to a tapping HR, or auscultated a simulated HR. They found that while study participants performed well at identifying HR > 100 beats per minute (bpm), almost two-thirds of participants failed to recognize a $\mathrm{HR}<60 \mathrm{bpm}$ for all methods of assessment (33). These findings emphasize the importance of early accurate objective HR monitoring during preterm infant transition for identification of infants who may require support or active resuscitation ( $\mathrm{HR}<60 \mathrm{bpm}$ ).

Pulse oximetry provides real-time accurate information about the HR of the preterm infant (34). However, pulse oximetry values are not available immediately as the sensor takes time to apply correctly and once applied, there is a delay before the monitor provides a reading. Limb perfusion will affect the time taken to achieve a pulse oximeter HR (34). Studies that have assessed the feasibility of obtaining prompt and reliable pulse oximetry readings have reported times to signal acquisition of between 1 and 2 min after delivery $(25,35)$. There is conflicting evidence as to whether quicker signal acquisitions are obtained by applying the sensor to the oximeter first or applying it to the infant first. Observational studies reported that the quickest method involved turning on the pulse oximeter prior to delivery, applying the sensor to the infant's right hand and then connecting the cable of the sensor to the oximeter. This results in mean readings within $25 \mathrm{~s}$ of reaching the resuscitation table in a research setting $(35,36)$. A recent RCT in the DR contradicted these findings and found significantly faster signal acquisition times in infants who 
had the sensor attached to the oximeter first (37). A limitation of pulse oximetry HR monitoring is that HRs $<100 \mathrm{bpm}$ are not consistently detected, and in a study by Kamlin et al. were only reported $89 \%$ of the time (34).

ECG monitoring can provide accurate $\mathrm{HR}$ values sooner than pulse oximetry following delivery $(34,38)$. The electrodes can be applied quickly, and there is little lapse in time waiting for monitor readings to appear. Katheria and colleagues reported that median times to acquire a signal from ECG and pulse oximetry were 4 and $32 \mathrm{~s}$, respectively (38). A limitation of ECG monitoring is the risk of pulseless electrical activity being misinterpreted as HR on ECG (39). Doppler ultrasound blood flow HR assessments in the DR are accurate compared with clinical and pulse oximetry assessments (40). Measurements can be taken through a polyethylene bag. However, clinical experience is required for accurate assessments and continuous measurements are not practical.

ECG monitoring cannot replace the need for pulse oximetry, which is necessary for $\mathrm{SpO}_{2}$ monitoring. However, given that ECG monitoring is more accurate than clinical estimations, ECG may prevent unnecessary interventions secondary to falsely low clinical HR estimations. Alternatively, it could increase interventions, which may or may not be appropriate, because of earlier accurate bradycardia detection. Although awaiting further evidence, there are a few important points to be made: initiation of ECG monitoring in the DR is easily achievable, is more accurate than clinical assessment and provides HR values more expediently than pulse oximetry. Therefore, at present, our practice is to have ECG monitoring available, as an adjunct to $\mathrm{SpO}_{2}$ monitoring, for all preterm deliveries $<32$ weeks gestation and in situations where advanced resuscitation is anticipated. Clinical trials are required to assess whether ECG monitoring affects the frequency of stabilization interventions, and ultimately whether its use affects stabilization outcomes.

\section{PERIPHERAL PERFUSION MONITORING}

Peripheral perfusion is determined by cardiac output and the caliber of the vessels transporting blood to the peripheries. Current clinical methodologies for non-invasive monitoring of peripheral perfusion include assessments of capillary refill time, peripheral temperatures, and palpation of peripheral pulses. Each method relies on subjective assessments and continuous measurements are impractical. Blood Pressure monitoring by Doppler and oscillometric methods are feasible in the DR and measurements for term infants have been reported (41). However, non-invasive measurements are not reliably consistent in preterm neonates, and invasive $\mathrm{BP}$ monitoring is not practical within the DR setting.

A recent review by Baik et al. identified four studies of echocardiographic monitoring during newborn stabilization (42). Each study assessed term infants only (43-46). Increased left ventricular output and stroke volume increased over the first $15 \mathrm{~min}$ of life (44-46) and one study reported an increase in left-to-right shunting across the ductus (46). The studies did not assess echocardiographic measurements of HR. The authors of the review concluded that echocardiographic monitoring in the DR would enhance our knowledge about "cardiac function changes" (42). However, it does not add useful clinical information during newborn stabilization, has not been assessed in preterm infants in the DR, and routine monitoring is not advised.

Non-invasive continuous cardiac output monitoring (NICOM) is an alternative method for assessing cardiac output in neonates. This technology is based on the assumption that changes in the resistance to electrical currents captured by electrodes on the thorax are directly related to changes in aortic volume during different stages of the cardiac cycle (30). NICOM measurements are feasible in neonates and correlate well with timed echocardiographic measurements $(47,48)$. However, NICOM may underestimate the actual CO value (47). Katheria and colleagues performed NICOM on 20 term infants during delayed cord clamping in the DR. They found that for the majority of infants, $\mathrm{CO}$ and stroke volume continued to increase in value from the second minute of life until the cord was clamped at $5 \mathrm{~min}$ (49). However, NICOM has yet to be assessed in preterm infants in the DR.

Perfusion index (PI) monitoring is a non-invasive method of assessing real-time peripheral perfusion, derived from, and displayed by the pulse oximeter. Pulse oximetry values are derived from red (660 nm) and infrared wavelengths (910-940 nm) (50). By using a third wavelength $(800 \mathrm{~nm})$, the overall hemoglobin content can be calculated and the pulsatile component of arterial blood can be distinguished from the non-pulsatile component (51). PI has been utilized to monitor preterm infants in a number of clinical areas (52). These include screening for congenital cardiac disease $(53,54)$, predicting low systemic blood flow $(55)$, and assessing perfusion following blood transfusion (56). However, while PI values are easily obtained in the DR, and normative values for preterm infants in the first day of life have been published $(57,58)$, they are highly variable in the immediate newborn period, for both term and preterm infants (59). There are neither trials comparing PI and clinical assessments of peripheral perfusion in preterm care nor trials assessing whether PI monitoring affects preterm outcomes. Therefore, evidence in favor or against PI monitoring in the DR is lacking.

\section{RESPIRATORY SUPPORT MONITORING}

Lung aeration is a critical point in newborn transition from fetal life. Newborn preterm infants are at an increased risk of needing respiratory support following delivery. Inadequate ventilation may result in hypoxia and resultant bradycardia. International guidelines advise a stepwise approach to achieving optimal ventilation following preterm delivery and prior to escalating cardiovascular support; therefore, positive pressure ventilation is the cornerstone of neonatal resuscitation $(60,61)$. It is provided either by mask ventilation, single or double nasal prongs, nasopharyngeal tube, or via an ET tube. Adequate airway ventilation is assessed clinically by chest rise, an increase in HR, and auscultation for air entry on both sides of the lung fields during DR stabilization. Visual assessments of chest rise are not reliable (62). After initiating mask ventilation and if the clinical response is suboptimal, guidelines advise repositioning of the mask to reduce leak, and airway opening manoeuvers to combat airway obstruction. If there is no clinical improvement after such interventions a definitive airway, 
in the form of ET intubation is advised (1). The mnemonic MRSOPA identifies these methods, improve Mask seal, Reposition the airway, Suction and/or Open the mouth, increase the inflation Pressure, and consider an Alternative airway.

Monitoring ventilatory efficacy in infants in the NICU is achieved by monitoring carbon dioxide $\left(\mathrm{CO}_{2}\right)$ levels, which can be achieved by measuring either transcutaneous or exhaled $\mathrm{CO}_{2}$ levels. There is very little information on $\mathrm{CO}_{2}$ assessment at birth. Studies in the DR have focused on exhaled $\mathrm{CO}_{2}$ detection, either by qualitative or semiquantitative disposable colorimetric $\mathrm{CO}_{2}$ detectors that change color upon contact with $\mathrm{CO}_{2}$, or quantitative capnography that provides a breath-by-breath end tidal $\mathrm{CO}_{2}$ measurement (63). Quantitative capnography is achieved either by mainstream capnography that utilizes an infrared absorption technique or by side stream capnography that continuously transports a sample of gas to a sampling cell within a monitor. Both capnography methods provide a continuous visual display of $\mathrm{CO}_{2}$ values (capnometry) (63). Absolute $\mathrm{CO}_{2}$ values may be unreliable in the immediate newborn period prior to the establishment of functional residual capacity. The lungs are partially fluid filled with resultant low pulmonary blood flow, and mask leak or rebreathing may also affect absolute values. Therefore, during DR mask ventilation, members of the resuscitation team are advised to follow the $\mathrm{CO}_{2}$ trace and not absolute $\mathrm{CO}_{2}$ values.

$\mathrm{CO}_{2}$ detectors are routinely used to aid in the assessment of correct ET tube placement (9). The use of $\mathrm{CO}_{2}$ detectors reduces the time to confirmation of ET tube placement and has been endorsed in resuscitation guidelines $(9,64)$. Their use may be limited by false negative readings, during cardiopulmonary arrest and severe airway obstruction $(65,66)$. Employing quantitative capnography following ET tube placement also results in quicker and more accurate confirmation of correct placement when compared with clinical assessments $(67,68)$. There are no clinical trials comparing $\mathrm{CO}_{2}$ detector and capnography use to confirm correct ET tube placement.

The use of $\mathrm{CO}_{2}$ detectors during facemask ventilation has been shown to help determine airway patency on an almost breath-tobreath basis and can aid resuscitation teams in recognizing airway obstruction and leak during DR positive pressure ventilation (69-72). $\mathrm{CO}_{2}$ detectors can also verify the efficacy of positive pressure facemask ventilation during sustained inflations, as practiced in some centers (73). However, $\mathrm{CO}_{2}$ monitoring is not routine during mask ventilation. van Os and colleagues displayed the benefits of $\mathrm{CO}_{2}$ detectors in helping resuscitation teams to recognize airway obstruction in 24 very low birth weight infants during positive pressure support in the DR (69). Quantitative capnography during mask ventilation has been shown to improve $\mathrm{CO}_{2}$ elimination with the onset of an infant's respiratory efforts; however, other authors have not found that it reduces the occurrence of hypocapnia or hypercapnia $(74,75)$. In a recent mannequin study, quantitative capnography was superior to $\mathrm{CO}_{2}$ detectors in improving efficacy of facemask ventilation (76). The results of the first clinical trial comparing the two methods of $\mathrm{CO}_{2}$ detection have yet to be published (CAPNO trial, unpublished, ISRCTN registration number: 10934870).

In the $\mathrm{DR}$, the user controls ventilation pressures delivered to the infants' lungs. The lungs of the preterm infant are susceptible to injury if exposed to high airway pressures. Immature animal models have shown that lung injury can occur after a few manual inflations at high pressure (77). On the other hand, facemask ventilation can be inadequate secondary to leak, even if the user is highly experienced $(78,79)$. In NICUs, ventilation adequacy can be assessed by respiratory function monitors (RFMs), which are incorporated into modern ventilators (80). They provide information not only on airway pressures but also on delivered tidal volumes. The monitor displays breathing pattern, tidal volumes, flow and pressure waves, and percentages of gas leak. RFMs have also been used to guide positive pressure ventilation in newborn resuscitations $(81,82)$. Schmolzer and colleagues found that RFM use during mask ventilation of preterm infants' results in significantly less leak, more mask adjustments and a lower rate of excessive tidal volume given (82). RFMs have also been used in a RCT, which displayed improved ventilation with masks compared with nasal tubes during stabilization of preterm infants (83). However, the use and interpretation of a RFM can be technically challenging for many inexperienced users. Milner and colleagues recently surveyed 51 neonatal trainees who had used RFMs during preterm stabilization (84). They found that the usefulness of respiratory function monitoring was dependent on the trainee's level of experience, and that appropriate responses to the RFM data were more frequent in the hands of senior clinicians compared with their junior colleagues. The composition of resuscitation teams may also play a role in the effectiveness of RFM use. Having an extra member present to interpret the RFM data and to advise on mask ventilation adjustments may improve its effectiveness but are difficult to justify in many centers with limited staff resources.

We look forward to further evidence on RFM use in preterm infants during DR stabilization, as they have the potential to monitor efficacy of ventilation while helping to protect premature lungs from unintended pressure related injury. However, at present, user difficulty remains a major limitation of RFM. In the meantime, we recommend that when positive pressure ventilation is initiated in the $\mathrm{DR}$, consideration should be given to monitor ventilation efficacy. The superiority of which device has yet to be elucidated. Confirmation of ET tube placement should be confirmed with a $\mathrm{CO}_{2}$ detector as per current international guidelines.

\section{NEUROMONITORING}

As survival rates and short-term outcomes continue to improve for preterm infants, focus has shifted on neuroprotection strategies. The recent SafeBoosC trial suggests that brain oxygenation monitoring in the NICU results in a reduction in the percentage of cerebral hypoxia sustained by preterm infants (85). At present, assessment of neurological well-being in the DR is based on clinical assessment alone. Assessments of muscle tone and reflex irritability are incorporated into the Apgar score (3). The brain is the most vulnerable organ in newborn infants. As survival of the most immature infants increase, concerns have been raised about increased risks of adverse neurodevelopmental outcomes (86, 87). Resuscitative measures should aim for the best possible neurological outcomes and a non-invasive, continuous measurement 
of cerebral oxygenation and activity would be ideal, but these currently are not routine and their role has yet to be evaluated.

Studies that sought to introduce neurological monitoring into the DR initially focused on cerebral blood flow using Doppler measurements of cerebral or carotid arteries (44, 88-92). Monitoring was found to be technically difficult and did not provide continuous data (93). Furthermore, there is conflicting evidence on the role of cerebral Doppler in identifying impaired cerebral autoregulation and resultant abnormal cranial ultrasound findings $(94,95)$.

More recently, researchers have concentrated on NIRS, which provides non-invasive monitoring of cerebral tissue oxygenation $\left(\mathrm{StO}_{2}\right)$ (96-109). NIRS utilizes the transparency of biological tissue to light in the near-infrared spectrum to measure tissue oxygenation (110). Cerebral tissue oxygen saturations in preterm infants have been shown to correlate well with superior vena cava flow and left ventricular output in the first days of life $(111,112)$. A number of studies have displayed the feasibility of obtaining cerebral oxygenation values using NIRS in the DR (93), and normative values for infants not requiring resuscitation have been published recently (103). However, the vast majority of these infants were full term infants. Table 2 summarizes the studies that have assessed NIRs in preterm infants in the DR.

Cerebral NIRS in the DR remains limited to research studies, but emerging data suggest that it may have a significant role in preterm stabilization in the future (113). NIRS measurements are readily obtained and, in a recent study conducted by this group, the NIRS values were obtained within seconds of application of the device in the DR, in contrast to the variable time for pulse oximetry readings. Binder et al. performed NIRS on 49 preterm infants in the immediate newborn period (100). They reported different $\mathrm{StO}_{2}$ transition time courses for infants requiring respiratory support and those with normal transitions. Infants requiring respiratory support had lower $\mathrm{StO}_{2}$ values over the first $10 \mathrm{~min}$ of life before reaching similar steady-state levels as their counterparts. Fuchs et al. reported $\mathrm{StO}_{2}$ values for 51 infants weighing $<1500 \mathrm{~g}$ (108). Low median $\mathrm{StO}_{2}$ values (37\%) were reported at $1 \mathrm{~min}$ of life, which continuously rose to steady-state levels $(61-84 \%)$ at $7 \mathrm{~min}$ of age. $\mathrm{StO}_{2}$ values did not differ in relation to the degree of resuscitation required in the $\mathrm{DR}$, but it was noted that two infants with subsequent IVHs had $\mathrm{StO}_{2}$ values that were $<10$ th percentile for their cohort. Kenosi et al. evaluated transitional cerebral NIRS values in preterm infants $<32$ weeks and found that preterm infants requiring $>30 \%$ oxygen to maintain peripheral saturations had a significantly higher degree of cerebral hypoxia (114). All infants initially received a $\mathrm{FiO}_{2}$ of 0.3 and oxygen was titrated according to standard resuscitation guidelines. There were no differences in cerebral hyperoxia between the two groups. These findings suggest that some preterm infants may require a more rapid increase in oxygen titration in the DR. At present, NIRS remains in the realm of DR research, but as more studies emerge, we believe that it will have a future role in monitoring preterm infants and guiding oxygen titration during DR resuscitations. Pichler and colleagues have recently performed a pilot RCT, in which infants $<34$ weeks were randomized in the DR either to cerebral NIRS and $\mathrm{SpO}_{2}$ monitoring or $\mathrm{SpO}_{2}$ monitoring alone to guide titration of oxygen therapy (115). They found that additional NIRS monitoring significantly reduced the time that infants' cerebral $\mathrm{StO}_{2}$ was $<10$ th percentile in the first $15 \mathrm{~min}$ of life. There was no difference in rates of IVH or abnormal neurological assessments at discharge. Further trials are required to ascertain how oxygen therapy should be guided when $\mathrm{StO}_{2}$ and $\mathrm{SpO}_{2}$ values are both available in the DR.

Cerebral NIRS monitoring may also have a future in providing outcome measures for DR studies. A recent RCT randomized infants (28-33+ 6 weeks gestation) to receive either one to three sustained lung inflations (SLIs) $\left(30 \mathrm{cmH}_{2} \mathrm{O}\right.$ for $\left.15 \mathrm{~s}\right)$ followed by standard respiratory care, or standard respiratory care only (116). Cerebral tissue oxygenation values were similar for both groups over the first $15 \mathrm{~min}$ of life. However, cerebral blood volume (CBV) patterns differed between groups. CBV decreased in the control group over time, but remained static in the intervention group who received SLIs. The authors hypothesized that differences may have been caused by impaired venous return secondary to increased thoracic pressures during SLI, with resultant cerebral

TABLE 2 | Summary of preterm DR NIRS studies.

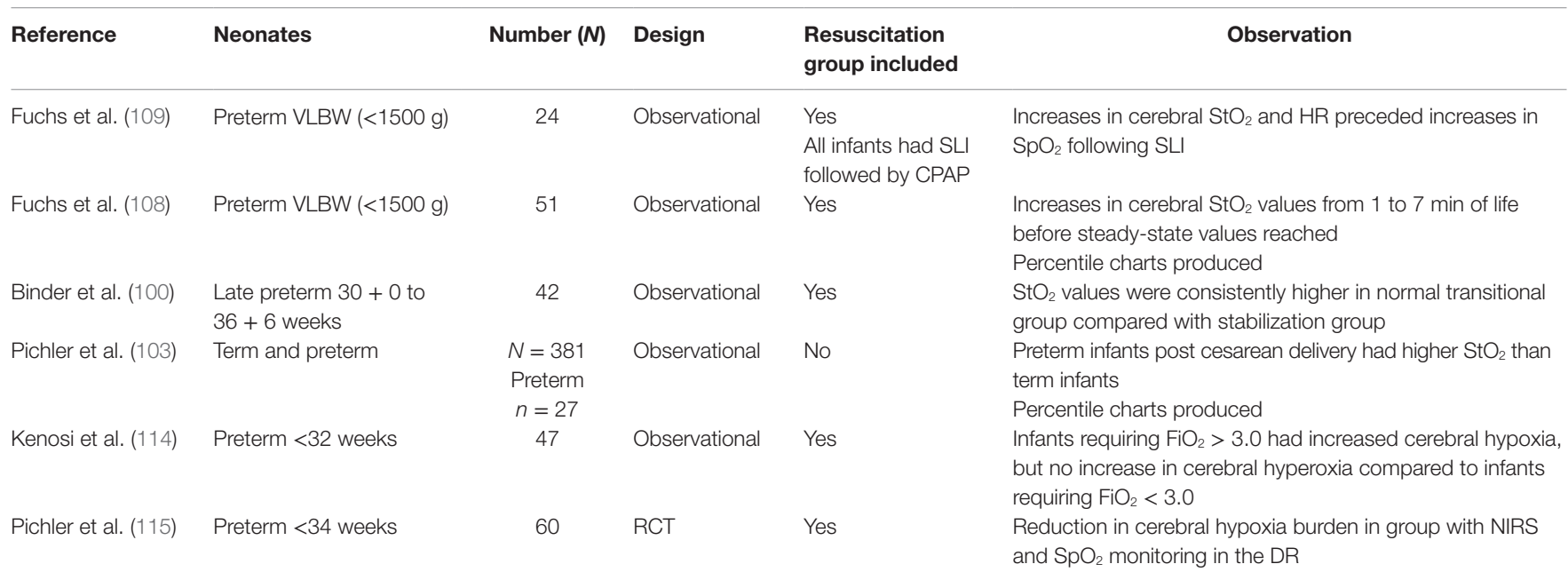


venous stasis. These findings highlight the importance of assessing cerebral hemodynamics during interventional DR studies.

Electroencephalography provides a real-time measure of electrocortical brain activity and has become more common in NICUs over the past two decades. In contrast to cerebral blood flow and NIRS, EEG has well-documented applications for the clinical management of newborn infants (117). Its usefulness includes monitoring infants with perinatal asphyxia (118-121), the detection of seizures (122-124), and more recently in assessing the long-term prognosis of both full term and preterm infants (125).

Despite its importance in monitoring the newborn brain in the NICU, only one study has assessed the feasibility of EEG monitoring in the DR. At present, we resuscitate infants at gestational ages that are at the borderline of viability without any information about brain activity. Pichler et al. performed aEEG (a modified form of EEG recording that filters, rectifies, amplifies, and compresses one to two channels of EEG activity) in infants $>34$ weeks gestation following elective cesarean section and achieved recordings after $3 \mathrm{~min}$ in some infants. However, continuous reliable data were difficult to obtain within their study of 63 infants (102). The two main factors restricting the introduction of EEG into the DR have been (1) the technical difficulties in acquiring reliable data in this setting and (2) the ability of people to interpret the data (93). Technical difficulties can be overcome especially given the recent introduction of easy to apply neonatal EEG sensors. The recent increase in research aiming to develop novel algorithms for neonatal EEG interpretation will also have an impact on DR brain monitoring in the near future (126). Further trials are required to assess the feasibility and utility of EEG recordings during transition for preterm infants.

\section{VIDEO RECORDING}

Video recordings provide objective measures of DR performance in the stabilization of preterm infants and can be utilized for education, research, and audits. Fifteen years ago, Carbine and colleagues reported that video recordings in the DR are feasible quality assurance tools (127). Video recordings can help assess neonatal teamwork in the DR, facilitate debriefings, and improve performance $(128,129)$.

Video analysis of newborn resuscitation and stabilization has shown that the availability of real-time information is less than optimal when compared with recommended guidelines $(127,130)$. In one study, $<50 \%$ of high-risk infants had a pulse oximeter reading $60 \mathrm{~s}$ after transfer to the resuscitation table (130). These findings are important, as they emphasize the need to maintain clinical skills given that the availability of real-time physiological data from monitors can be delayed. In addition, they suggest that the feasibility of enacting current resuscitation guidelines should be constantly reassessed. Real-time video communication has been shown to improve adherence to neonatal resuscitation guidelines and may provide support for resuscitations in peripheral maternity centers (131). Nadler and colleagues assessed 19 neonatal newborn resuscitations, before and after the introduction of video recordings to facilitate debriefings. They found that all measures of teamwork improved after the intervention (129). Prior to introducing video recordings into DRs, ethical, legal, and practical obstacles must be overcome at a local level. These obstacles leave video recordings in the realms of research at present, despite their known practical benefits (132).

\section{CONCLUSION}

Preterm infant monitoring during DR stabilization remains relatively basic when compared to the enhanced monitoring available in the NICU. At present, clinical assessments are the dominant paradigm; however, these have many limitations and so additional monitoring is required. All preterm infant stabilizations should have pulse oximetry monitoring to monitor $\mathrm{HR}$ and $\mathrm{SpO}_{2}$. ECG monitoring should also be available as an adjunct to ongoing clinical assessment and pulse oximetry when advanced resuscitation is anticipated. We believe that such monitoring should be initiated immediately after delivery. We also advise, while awaiting further research, that if positive pressure ventilation is commenced, either capnography or a RFM should be considered to monitor ventilation efficacy. Cerebral oxygenation monitoring, by NIRS and/or EEG, may have an important role to play in newborn transition. We look forward to further research in this area and recognize the challenges in performing such studies.

\section{AUTHOR CONTRIBUTIONS}

ED conceived and designed the review. DF drafted the initial manuscript. All authors (DF, CR, GB, and ED) critically revised the manuscript for important intellectual content, agreed on the final manuscript, and approved its submission for publication.

\section{FUNDING}

This review was supported by a Science Foundation Ireland Research Centre Award (INFANT-12/RC/2272).

\section{REFERENCES}

1. Wyllie J, Bruinenberg J, Roehr CC, Rudiger M, Trevisanuto D, Urlesberger B. European resuscitation council guidelines for resuscitation 2015: section 7. Resuscitation and support of transition of babies at birth. Resuscitation (2015) 95:249-63. doi:10.1016/j.resuscitation.2015.07.029

2. Bradley F, Field J. Evidence-based medicine. Lancet (1995) 346(8978):838-9.

3. ApgarV.Aproposalforanewmethodofevaluationofthenewborninfant.CurrRes Anesth Analg (1953) 32(4):260-7. doi:10.1213/00000539-195301000-00041

4. Casey BM, McIntire DD, Leveno KJ. The continuing value of the Apgar score for the assessment of newborn infants. N Engl J Med (2001) 344(7):467-71. doi:10.1056/NEJM200102153440701

5. Moster D, Lie RT, Irgens LM, Bjerkedal T, Markestad T. The association of Apgar score with subsequent death and cerebral palsy: a population-based study in term infants. J Pediatr (2001) 138(6):798-803. doi:10.1067/mpd.2001.114694

6. Thorngren-Jerneck K, Herbst A. Low 5-minute Apgar score: a population-based register study of 1 million term births. Obstet Gynecol (2001) 98(1):65-70. doi:10.1097/00006250-200107000-00012 
7. Apgar V. The newborn (Apgar) scoring system. Reflections and advice. Pediatr Clin North Am (1966) 13(3):645-50.

8. Apgar V, Holaday DA, James LS, Weisbrot IM, Berrien C. Evaluation of the newborn infant; second report. J Am Med Assoc (1958) 168(15):1985-8. doi:10.1001/jama.1958.03000150027007

9. Kattwinkel J, Perlman JM, Aziz K, Colby C, Fairchild K, Gallagher J, et al. Neonatal resuscitation: 2010 American Heart Association Guidelines for Cardiopulmonary Resuscitation and Emergency Cardiovascular Care. Pediatrics (2010) 126(5):e1400-13. doi:10.1542/peds.2010-2972E

10. Perlman JM, Wyllie J, Kattwinkel J, Atkins DL, Chameides L, Goldsmith JP, et al. Neonatal resuscitation: 2010 International Consensus on Cardiopulmonary Resuscitation and Emergency Cardiovascular Care Science with Treatment Recommendations. Pediatrics (2010) 126(5):e1319-44. doi:10.1542/peds.2010-2972B

11. Perlman JM, Wyllie J, Kattwinkel J, Atkins DL, Chameides L, Goldsmith JP, et al. Part 11: neonatal resuscitation: 2010 International Consensus on Cardiopulmonary Resuscitation and Emergency Cardiovascular Care Science with Treatment Recommendations. Circulation (2010) 122(16 Suppl 2):S516-38. doi:10.1161/CIRCULATIONAHA.110.971127

12. Clark DA, Hakanson DO. The inaccuracy of Apgar scoring. J Perinatol (1988) 8(3):203-5.

13. O’Donnell CP, Kamlin CO, Davis PG, Carlin JB, Morley CJ. Interobserver variability of the 5-minute Apgar score. J Pediatr (2006) 149(4):486-9. doi:10.1016/j.jpeds.2006.05.040

14. Singh J, Fanaroff J, Andrews B, Caldarelli L, Lagatta J, Plesha-Troyke S, et al. Resuscitation in the "gray zone" of viability: determining physician preferences and predicting infant outcomes. Pediatrics (2007) 120(3):519-26. doi:10.1542/peds.2006-2966

15. Manley BJ, Dawson JA, Kamlin CO, Donath SM, Morley CJ, Davis PG. Clinical assessment of extremely premature infants in the delivery room is a poor predictor of survival. Pediatrics (2010) 125(3):e559-64. doi:10.1542/ peds.2009-1307

16. Rudiger M, Wauer RR, Schmidt K, Kuster H. The Apgar score. Pediatrics (2006) 118(3):1314-5; author reply 5-6. doi:10.1542/peds.2006-1254

17. American Academy of Pediatrics Committee on Fetus and Newborn, American College of Obstetricians and Gynecologists and Committee on Obstetric Practice. The Apgar score. Pediatrics (2006) 117(4):1444-7. doi:10.1542/peds.2006-0325

18. Rudiger M, Braun N, Aranda J, Aguar M, Bergert R, Bystricka A, et al. Neonatal assessment in the delivery room - trial to evaluate a specified type of Apgar (TEST-Apgar). BMC Pediatr (2015) 15:18. doi:10.1186/s12887-015-0334-7

19. O’Donnell CP, Kamlin CO, Davis PG, Carlin JB, Morley CJ. Clinical assessment of infant colour at delivery. Arch Dis Child Fetal Neonatal Ed (2007) 92(6):F465-7. doi:10.1136/adc.2007.120634

20. Allen J. Photoplethysmography and its application in clinical physiological measurement. Physiol Meas (2007) 28(3):R1-39. doi:10.1088/0967-3334/28/3/R01

21. Tin W, Lal M. Principles of pulse oximetry and its clinical application in neonatal medicine. Semin Fetal Neonatal Med (2015) 20(3):192-7. doi:10.1016/j. siny.2015.01.006

22. Durand M, Ramanathan R. Pulse oximetry for continuous oxygen monitoring in sick newborn infants. J Pediatr (1986) 109(6):1052-6. doi:10.1016/ S0022-3476(86)80298-0

23. Vijayakumar E, Ward GJ, Bullock CE, Patterson ML. Pulse oximetry in infants of $<1500 \mathrm{gm}$ birth weight on supplemental oxygen: a national survey. J Perinatol (1997) 17(5):341-5.

24. Dawson JA, Kamlin CO, Vento M, Wong C, Cole TJ, Donath SM, et al. Defining the reference range for oxygen saturation for infants after birth. Pediatrics (2010) 125(6):e1340-7. doi:10.1542/peds.2009-1510

25. Dawson JA, Kamlin CO, Wong C, te Pas AB, O'Donnell CP, Donath SM, et al. Oxygen saturation and heart rate during delivery room resuscitation of infants $<30$ weeks' gestation with air or 100\% oxygen. Arch Dis Child Fetal Neonatal Ed (2009) 94(2):F87-91. doi:10.1136/adc.2008.141341

26. Smit M, Dawson JA, Ganzeboom A, Hooper SB, van Roosmalen J, te Pas AB. Pulse oximetry in newborns with delayed cord clamping and immediate skin-to-skin contact. Arch Dis Child Fetal Neonatal Ed (2014) 99(4):F309-14. doi:10.1136/archdischild-2013-305484

27. Hay WW Jr. The uses, benefits, and limitations of pulse oximetry in neonatal medicine: consensus on key issues. J Perinatol (1987) 7(4):347-9.
28. Hay WW Jr. Physiology of oxygenation and its relation to pulse oximetry in neonates. J Perinatol (1987) 7(4):309-19.

29. Wasunna A, Whitelaw AG. Pulse oximetry in preterm infants. Arch Dis Child (1987) 62(9):957-8. doi:10.1136/adc.62.9.957

30. Saugstad OD. Bronchopulmonary dysplasia-oxidative stress and antioxidants. Semin Neonatol (2003) 8(1):39-49. doi:10.1016/S1084-2756(02)00194-X

31. Owen CJ, Wyllie JP. Determination of heart rate in the baby at birth. Resuscitation (2004) 60(2):213-7. doi:10.1016/j.resuscitation.2003.10.002

32. Kamlin CO, O'Donnell CP, Everest NJ, Davis PG, Morley CJ. Accuracy of clinical assessment of infant heart rate in the delivery room. Resuscitation (2006) 71(3):319-21. doi:10.1016/j.resuscitation.2006.04.015

33. Hawkes GA, Hawkes CP, Kenosi M, Demeulemeester J, Livingstone V, Ryan CA, et al. Auscultate, palpate and tap: time to re-evaluate. Acta Paediatr (2015) 105:178-82. doi:10.1111/apa.13169

34. Kamlin CO, Dawson JA, O’Donnell CP, Morley CJ, Donath SM, Sekhon J, et al. Accuracy of pulse oximetry measurement of heart rate of newborn infants in the delivery room. J Pediatr (2008) 152(6):756-60. doi:10.1016/j. jpeds.2008.01.002

35. O’Donnell CP, Kamlin CO, Davis PG, Morley CJ. Feasibility of and delay in obtaining pulse oximetry during neonatal resuscitation. J Pediatr (2005) 147(5):698-9. doi:10.1016/j.jpeds.2005.07.025

36. O’Donnell CP, Kamlin CO, Davis PG, Morley CJ. Obtaining pulse oximetry data in neonates: a randomised crossover study of sensor application techniques. Arch Dis Child Fetal Neonatal Ed (2005) 90(1):F84-5. doi:10.1136/ adc. 2004.058925

37. Louis D, Sundaram V, Kumar P. Pulse oximeter sensor application during neonatal resuscitation: a randomized controlled trial. Pediatrics (2014) 133(3):476-82. doi:10.1542/peds.2013-2175

38. Katheria A, Rich W, Finer N. Electrocardiogram provides a continuous heart rate faster than oximetry during neonatal resuscitation. Pediatrics (2012) 130(5):e1177-81. doi:10.1542/peds.2012-0784

39. Myerburg RJ, Halperin H, Egan DA, Boineau R, Chugh SS, Gillis AM, et al. Pulseless electric activity: definition, causes, mechanisms, management, and research priorities for the next decade: report from a National Heart, Lung, and Blood Institute Workshop. Circulation (2013) 128(23):2532-41. doi:10.1161/CIRCULATIONAHA.113.004490

40. Phillipos E, Solevag AL, Pichler G, Aziz K, van Os S, O’Reilly M, et al. Heart rate assessment immediately after birth. Neonatology (2016) 109(2):130-8. doi:10.1159/000441940

41. Salihoglu O, Can E, Beskardes A, Koc BS, Tan I, Can G, et al. Delivery room blood pressure percentiles of healthy, singleton, liveborn neonates. Pediatr Int (2012) 54(2):182-9. doi:10.1111/j.1442-200X.2011.03520.x

42. Baik N, Urlesberger B, Schwaberger B, Freidl T, Schmolzer GM, Pichler G. Cardiocirculatory monitoring during immediate fetal-to-neonatal transition: a systematic qualitative review of the literature. Neonatology (2015) 107(2):100-7. doi:10.1159/000368042

43. Winberg P, Jansson M, Marions L, Lundell BP. Left ventricular output during postnatal circulatory adaptation in healthy infants born at full term. Arch Dis Child (1989) 64(10 Spec No):1374-8. doi:10.1136/adc.64.10_Spec_No.1374

44. Noori S, Wlodaver A, Gottipati V, McCoy M, Schultz D, Escobedo M. Transitional changes in cardiac and cerebral hemodynamics in term neonates at birth. J Pediatr (2012) 160(6):943-8. doi:10.1016/j.jpeds.2011.12.008

45. van Vonderen JJ, Roest AA, Siew ML, Blom NA, van Lith JM, Walther FJ, et al. Noninvasive measurements of hemodynamic transition directly after birth. Pediatr Res (2014) 75(3):448-52. doi:10.1038/pr.2013.241

46. van Vonderen JJ, te Pas AB, Kolster-Bijdevaate C, van Lith JM, Blom NA, Hooper SB, et al. Non-invasive measurements of ductus arteriosus flow directly after birth. Arch Dis Child Fetal Neonatal Ed (2014) 99(5):F408-12. doi:10.1136/archdischild-2014-306033

47. Weisz DE, Jain A, McNamara PJ, EL-Khuffash A. Non-invasive cardiac output monitoring in neonates using bioreactance: a comparison with echocardiography. Neonatology (2012) 102(1):61-7. doi:10.1159/000337295

48. Weisz DE, Jain A, Ting J, McNamara PJ, El-Khuffash A. Non-invasive cardiac output monitoring in preterm infants undergoing patent ductus arteriosus ligation: a comparison with echocardiography. Neonatology (2014) 106(4):330-6. doi:10.1159/000365278

49. Katheria AC, Wozniak M, Harari D, Arnell K, Petruzzelli D, Finer NN. Measuring Cardiac Changes Using Electrical Impedance During Delayed Cord 
Clamping: A Feasibility Trial Guidelines on Basic Newborn Resuscitation. Geneva: World Health Organization (2015). p. 1-6.

50. Sinex JE. Pulse oximetry: principles and limitations. Am J Emerg Med (1999) 17(1):59-67. doi:10.1016/S0735-6757(99)90019-0

51. Lima A, Bakker J. Noninvasive monitoring of peripheral perfusion. Intensive Care Med (2005) 31(10):1316-26. doi:10.1007/s00134-005-2790-2

52. Piasek CZ, Van Bel F, Sola A. Perfusion index in newborn infants: a noninvasive tool for neonatal monitoring. Acta Paediatr (2014) 103(5):468-73. doi:10.1111/apa.12574

53. Jegatheesan P, Song D, Angell C, Devarajan K, Govindaswami B. Oxygen saturation nomogram in newborns screened for critical congenital heart disease. Pediatrics (2013) 131(6):e1803-10. doi:10.1542/peds.2012-3320

54. Granelli A, Ostman-Smith I. Noninvasive peripheral perfusion index as a possible tool for screening for critical left heart obstruction. Acta Paediatr (2007) 96(10):1455-9. doi:10.1111/j.1651-2227.2007.00439.x

55. Takahashi S, Kakiuchi S, Nanba Y, Tsukamoto K, Nakamura T, Ito Y. The perfusion index derived from a pulse oximeter for predicting low superior vena cava flow in very low birth weight infants. J Perinatol (2010) 30(4):265-9. doi:10.1038/jp.2009.159

56. Kanmaz HG, Sarikabadayi YU, Canpolat E, Altug N, Oguz SS, Dilmen $\mathrm{U}$. Effects of red cell transfusion on cardiac output and perfusion index in preterm infants. Early Hum Dev (2013) 89(9):683-6. doi:10.1016/j. earlhumdev.2013.04.018

57. Hakan N, Dilli D, Zenciroglu A, Aydin M, Okumus N. Reference values of perfusion indices in hemodynamically stable newborns during the early neonatal period. Eur J Pediatr (2014) 173(5):597-602. doi:10.1007/ s00431-013-2224-z

58. Vidal M, Ferragu F, Durand S, Baleine J, Batista-Novais AR, Cambonie G. Perfusion index and its dynamic changes in preterm neonates with patent ductus arteriosus. Acta Paediatr (2013) 102(4):373-8. doi:10.1111/ apa.12130

59. Hawkes GA, O’Toole JM, Kenosi M, Ryan CA, Dempsey EM. Perfusion index in the preterm infant immediately after birth. Early Hum Dev (2015) 91(8):463-5. doi:10.1016/j.earlhumdev.2015.05.003

60. Singhal N, McMillan DD, Yee WH, Akierman AR, Yee YJ. Evaluation of the effectiveness of the standardized neonatal resuscitation program. J Perinatol (2001) 21(6):388-92. doi:10.1038/sj.jp.7210551

61. Bennett S, Finer NN, Rich W, Vaucher Y. A comparison of three neonatal resuscitation devices. Resuscitation (2005) 67(1):113-8. doi:10.1016/j. resuscitation.2005.02.016

62. Poulton DA, Schmolzer GM, Morley CJ, Davis PG. Assessment of chest rise during mask ventilation of preterm infants in the delivery room. Resuscitation (2011) 82(2):175-9. doi:10.1016/j.resuscitation.2010.10.012

63. Hawkes GA, Kelleher J, Ryan CA, Dempsey EM. A review of carbon dioxide monitoring in preterm newborns in the delivery room. Resuscitation (2014) 85(10):1315-9. doi:10.1016/j.resuscitation.2014.07.012

64. Aziz HF, Martin JB, Moore JJ. The pediatric disposable end-tidal carbon dioxide detector role in endotracheal intubation in newborns. J Perinatol (1999) 19(2):110-3. doi:10.1038/sj.jp.7200136

65. Molloy EJ, Deakins K. Are carbon dioxide detectors useful in neonates? Arch Dis Child Fetal Neonatal Ed (2006) 91(4):F295-8. doi:10.1136/ adc. 2005.082008

66. Schmolzer GM, Poulton DA, Dawson JA, Kamlin CO, Morley CJ, Davis $\mathrm{PG}$. Assessment of flow waves and colorimetric $\mathrm{CO}_{2}$ detector for endotracheal tube placement during neonatal resuscitation. Resuscitation (2011) 82(3):307-12. doi:10.1016/j.resuscitation.2010.11.008

67. Hosono S, Inami I, Fujita H, Minato M, Takahashi S, Mugishima H. A role of end-tidal $\mathrm{CO}(2)$ monitoring for assessment of tracheal intubations in very low birth weight infants during neonatal resuscitation at birth. J Perinat Med (2009) 37(1):79-84. doi:10.1515/JPM.2009.017

68. Repetto JE, Donohue P-CP, Baker SF, Kelly L, Nogee LM. Use of capnography in the delivery room for assessment of endotracheal tube placement. J Perinatol (2001) 21(5):284-7. doi:10.1038/sj.jp.7210534

69. van Os S, Cheung PY, Pichler G, Aziz K, O’Reilly M, Schmolzer GM. Exhaled carbon dioxide can be used to guide respiratory support in the delivery room. Acta Paediatr (2014) 103(8):796-806. doi:10.1111/apa.12650

70. O’Reilly M, Cheung PY, Aziz K, Schmolzer GM. Short- and intermediate-term outcomes of preterm infants receiving positive pressure ventilation in the delivery room. Crit Care Res Pract (2013) 2013:715915. doi:10.1155/2013/715915

71. Leone TA, Lange A, Rich W, Finer NN. Disposable colorimetric carbon dioxide detector use as an indicator of a patent airway during noninvasive mask ventilation. Pediatrics (2006) 118(1):e202-4. doi:10.1542/peds.2005-2493

72. Finer NN, Rich W, Wang C, Leone T. Airway obstruction during mask ventilation of very low birth weight infants during neonatal resuscitation. Pediatrics (2009) 123(3):865-9. doi:10.1542/peds.2008-0560

73. van Vonderen JJ, Lista G, Cavigioli F, Hooper SB, te Pas AB. Effectivity of ventilation by measuring expired $\mathrm{CO}_{2}$ and RIP during stabilisation of preterm infants at birth. Arch Dis Child Fetal Neonatal Ed (2015) 100(6):F514-8. doi:10.1136/archdischild-2014-307412

74. Kong JY, Rich W, Finer NN, Leone TA. Quantitative end-tidal carbon dioxide monitoring in the delivery room: a randomized controlled trial. J Pediatr (2013) 163(1):104-8.e1. doi:10.1016/j.jpeds.2012.12.016

75. Murthy V, O’Rourke-Potocki A, Dattani N, Fox GF, Campbell ME, Milner $\mathrm{AD}$, et al. End tidal carbon dioxide levels during the resuscitation of prematurely born infants. Early Hum Dev (2012) 88(10):783-7. doi:10.1016/j. earlhumdev.2012.05.003

76. Hawkes GA, Kenosi M, Ryan CA, Dempsey EM. Quantitative or qualitative carbon dioxide monitoring for manual ventilation: a mannequin study. Acta Paediatr (2015) 104(4):e148-51. doi:10.1111/apa.12868

77. Bjorklund LJ, Ingimarsson J, Curstedt T, John J, Robertson B, Werner O, et al. Manual ventilation with a few large breaths at birth compromises the therapeutic effect of subsequent surfactant replacement in immature lambs. Pediatr Res (1997) 42(3):348-55. doi:10.1203/00006450-199709000-00016

78. O'Donnell CP, Kamlin CO, Davis PG, Morley CJ. Neonatal resuscitation 1: a model to measure inspired and expired tidal volumes and assess leakage at the face mask. Arch Dis Child Fetal Neonatal Ed (2005) 90(5):F388-91. doi:10.1136/adc.2004.064683

79. Schmolzer GM, Kamlin OC, O’Donnell CP, Dawson JA, Morley CJ, Davis PG. Assessment of tidal volume and gas leak during mask ventilation of preterm infants in the delivery room. Arch Dis Child Fetal Neonatal Ed (2010) 95(6):F393-7. doi:10.1136/adc.2009.174003

80. Bhutani VK. Clinical applications of pulmonary function and graphics. Semin Neonatol (2002) 7(5):391-9. doi:10.1053/siny.2002.0133

81. Schmolzer GM, Morley CJ, Davis PG. Respiratory function monitoring to reduce mortality and morbidity in newborn infants receiving resuscitation. Cochrane Database Syst Rev (2010) (9):CD008437. doi:10.1002/14651858. CD008437.pub2

82. Schmolzer GM, Morley CJ, Wong C, Dawson JA, Kamlin CO, Donath SM, et al. Respiratory function monitor guidance of mask ventilation in the delivery room: a feasibility study. J Pediatr (2012) 160(3):377-81.e2. doi:10.1016/j. jpeds.2011.09.017

83. van Vonderen JJ, Kamlin CO, Dawson JA, Walther FJ, Davis PG, te Pas AB. Mask versus nasal tube for stabilization of preterm infants at birth: respiratory function measurements. J Pediatr (2015) 167(1):81-5.e1. doi:10.1016/j. jpeds.2015.04.003

84. Milner A, Murthy V, Bhat P, Fox G, Campbell ME, Milner AD, et al. Evaluation of respiratory function monitoring at the resuscitation of prematurely born infants. Eur J Pediatr (2015) 174(2):205-8. doi:10.1007/s00431-014-2379-2

85. Plomgaard AM, van Oeveren W, Petersen TH, Alderliesten T, Austin T, van Bel F, et al. The SafeBoosC II randomised trial: treatment guided by near-infrared spectroscopy reduces cerebral hypoxia without changing early biomarkers of brain injury. Pediatr Res (2015). doi:10.1038/pr.2015.266

86. Duerden EG, Taylor MJ, Miller SP. Brain development in infants born preterm: looking beyond injury. Semin Pediatr Neurol (2013) 20(2):65-74. doi:10.1016/j.spen.2013.06.007

87. Moore T, Hennessy EM, Myles J, Johnson SJ, Draper ES, Costeloe KL, et al. Neurological and developmental outcome in extremely preterm children born in England in 1995 and 2006: the EPICure studies. BMJ (2012) 345:e7961. doi:10.1136/bmj.e7961

88. Sonesson SE, Winberg P, Lundell BP. Early postnatal changes in intracranial arterial blood flow velocities in term infants. Pediatr Res (1987) 22(4):461-4. doi:10.1203/00006450-198710000-00020

89. Maesel A, Sladkevicius P, Gudmundsson S, Mars al K. Mode of delivery and perinatal cerebral blood flow. Early Hum Dev (1996) 44(3):179-85. doi:10.1016/0378-3782(95)01707-0 
90. Maesel A, Sladkevicius P, Valentin L, Marsal K. Fetal cerebral blood flow velocity during labor and the early neonatal period. Ultrasound Obstet Gynecol (1994) 4(5):372-6. doi:10.1046/j.1469-0705.1994.04050372.x

91. Ipsiroglu OS, Stockler S, Hausler MC, Kainer F, Rosegger H, Weiss PA, et al. Cerebral blood flow velocities in the first minutes of life. Eur J Pediatr (1993) 152(3):269-70. doi:10.1007/BF01956162

92. Jorch G, Rabe H, Michel E, Engels M, Schulz V, Hentschel R, et al. Resuscitation of the very immature infant: cerebral Doppler flow velocities in the first 20 minutes of life. Biol Neonate (1993) 64(4):215-20. doi:10.1159/000243992

93. Pichler G, Cheung PY, Aziz K, Urlesberger B, Schmolzer GM. How to monitor the brain during immediate neonatal transition and resuscitation? A systematic qualitative review of the literature. Neonatology (2014) 105(3):205-10. doi: $10.1159 / 000357162$

94. Rennie JM, Coughtrey H, Morley R, Evans DH. Comparison of cerebral blood flow velocity estimation with cranial ultrasound imaging for early prediction of outcome in preterm infants. J Clin Ultrasound (1995) 23(1):27-31. doi:10.1002/jcu.1870230106

95. Boylan GB, Young K, Panerai RB, Rennie JM, Evans DH. Dynamic cerebral autoregulation in sick newborn infants. Pediatr Res (2000) 48(1):12-7. doi:10.1203/00006450-200007000-00005

96. Peebles DM, Edwards AD, Wyatt JS, Cope M, Delpy DT, Reynold EO. Changes in human fetal cerebral oxygenation and blood volume during delivery. Am JObstet Gynecol (1992) 167(6):1916-7. doi:10.1016/0002-9378(92)91808-N

97. Isobe K, Kusaka T, Fujikawa Y, Kondo M, Kawada K, Yasuda S, et al. Changes in cerebral hemoglobin concentration and oxygen saturation immediately after birth in the human neonate using full-spectrum near infrared spectroscopy. J Biomed Opt (2000) 5(3):283-6. doi:10.1117/1.429997

98. Isobe K, Kusaka T, Fujikawa Y, Okubo K, Nagano K, Yasuda S, et al. Measurement of cerebral oxygenation in neonates after vaginal delivery and cesarean section using full-spectrum near infrared spectroscopy. Comp Biochem Physiol A Mol Integr Physiol (2002) 132(1):133-8. doi:10.1016/ S1095-6433(01)00539-6

99. Fauchere JC, Schulz G, Haensse D, Keller E, Ersch J, Bucher HU, et al. Nearinfrared spectroscopy measurements of cerebral oxygenation in newborns during immediate postnatal adaptation. J Pediatr (2010) 156(3):372-6. doi:10.1016/j.jpeds.2009.09.050

100. Binder C, Urlesberger B, Avian A, Pocivalnik M, Muller W, Pichler G. Cerebral and peripheral regional oxygen saturation during postnatal transition in preterm neonates. J Pediatr (2013) 163(2):394-9. doi:10.1016/j. jpeds.2013.01.026

101. Kratky E, Pichler G, Rehak T, Avian A, Pocivalnik M, Muller W, et al. Regional cerebral oxygen saturation in newborn infants in the first 15 min of life after vaginal delivery. Physiol Meas (2012) 33(1):95-102. doi:10.1088/0967-3334/33/1/95

102. Pichler G, Avian A, Binder C, Zotter H, Schmolzer GM, Morris N, et al. aEEG and NIRS during transition and resuscitation after birth: promising additional tools; an observational study. Resuscitation (2013) 84(7):974-8. doi:10.1016/j.resuscitation.2012.12.025

103. Pichler G, Binder C, Avian A, Beckenbach E, Schmolzer GM, Urlesberger B. Reference ranges for regional cerebral tissue oxygen saturation and fractional oxygen extraction in neonates during immediate transition after birth. J Pediatr (2013) 163(6):1558-63. doi:10.1016/j.jpeds.2013.07.007

104. Urlesberger B, Brandner A, Pocivalnik M, Koestenberger M, Morris N, Pichler G. A left-to-right shunt via the ductus arteriosus is associated with increased regional cerebral oxygen saturation during neonatal transition. Neonatology (2013) 103(4):259-63. doi:10.1159/000346384

105. Urlesberger B, Grossauer K, Pocivalnik M, Avian A, Muller W, Pichler G. Regional oxygen saturation of the brain and peripheral tissue during birth transition of term infants. J Pediatr (2010) 157(5):740-4. doi:10.1016/j. jpeds.2010.05.013

106. Urlesberger B, Kratky E, Rehak T, Pocivalnik M, Avian A, Czihak J, et al. Regional oxygen saturation of the brain during birth transition of term infants: comparison between elective cesarean and vaginal deliveries. J Pediatr (2011) 159(3):404-8. doi:10.1016/j.jpeds.2011.02.030

107. Almaazmi M, Schmid MB, Havers S, Reister F, Lindner W, Mayer B, et al. Cerebral near-infrared spectroscopy during transition of healthy term newborns. Neonatology (2013) 103(4):246-51. doi:10.1159/000345926
108. Fuchs H, Lindner W, Buschko A, Almazam M, Hummler HD, Schmid MB. Brain oxygenation monitoring during neonatal resuscitation of very low birth weight infants. J Perinatol (2012) 32(5):356-62. doi:10.1038/jp. 2011.110

109. Fuchs H, Lindner W, Buschko A, Trischberger T, Schmid M, Hummler HD. Cerebral oxygenation in very low birth weight infants supported with sustained lung inflations after birth. Pediatr Res (2011) 70(2):176-80. doi:10.1038/pr.2011.401

110. Menke J, Voss U, Moller G, Jorch G. Reproducibility of cerebral near infrared spectroscopy in neonates. Biol Neonate (2003) 83(1):6-11. doi:10.1159/000067006

111. Moran M, Miletin J, Pichova K, Dempsey EM. Cerebral tissue oxygenation index and superior vena cava blood flow in the very low birth weight infant. Acta Paediatr (2009) 98(1):43-6. doi:10.1111/j.1651-2227.2008.01006.x

112. Takami T, Sunohara D, Kondo A, Mizukaki N, Suganami Y, Takei Y, et al. Changes in cerebral perfusion in extremely LBW infants during the first $72 \mathrm{~h}$ after birth. Pediatr Res (2010) 68(5):435-9. doi:10.1203/ PDR.0b013e3181f2bd4d

113. Kenosi M, Naulaers G, Ryan CA, Dempsey EM. Current research suggests that the future looks brighter for cerebral oxygenation monitoring in preterm infants. Acta Paediatr (2015) 104(3):225-31. doi:10.1111/apa.12906

114. Kenosi M, O’Toole JM, Livingston V, Hawkes GA, Boylan GB, O'Halloran $\mathrm{KD}$, et al. Effects of fractional inspired oxygen on cerebral oxygenation in preterm infants following delivery. J Pediatr (2015) 167:1007-12. doi:10.1016/j.jpeds.2015.07.063

115. Pichler G, Urlesberger B, Baik N, Schwaberger B, Binder-Heschl C, Avian $A$, et al. Cerebral oxygen saturation to guide oxygen delivery in preterm neonates for the immediate transition after birth: a 2-center randomized controlled pilot feasibility trial. J Pediatr (2015) 170:73-8. doi:10.1016/j. jpeds.2015.11.053

116. Schwaberger B, Pichler G, Avian A, Binder-Heschl C, Baik N, Urlesberger B. Do sustained lung inflations during neonatal resuscitation affect cerebral blood volume in preterm infants? A randomized controlled pilot study. PLoS One (2015) 10(9):e0138964. doi:10.1371/journal.pone.0138964

117. Toet MC, Lemmers PM. Brain monitoring in neonates. Early Hum Dev (2009) 85(2):77-84. doi:10.1016/j.earlhumdev.2008.11.007

118. Hellstrom-Westas L, Rosen I. Continuous brain-function monitoring: state of the art in clinical practice. Semin Fetal Neonatal Med (2006) 11(6):503-11. doi:10.1016/j.siny.2006.07.011

119. al Naqeeb N, Edwards AD, Cowan FM, Azzopardi D. Assessment of neonatal encephalopathy by amplitude-integrated electroencephalography. Pediatrics (1999) 103(6 Pt 1):1263-71. doi:10.1542/peds.103.6.1263

120. Shany E, Goldstein E, Khvatskin S, Friger MD, Heiman N, Goldstein M, et al. Predictive value of amplitude-integrated electroencephalography pattern and voltage in asphyxiated term infants. Pediatr Neurol (2006) 35(5):335-42. doi:10.1016/j.pediatrneurol.2006.06.007

121. Toet MC, Lemmers PM, van Schelven LJ, van Bel F. Cerebral oxygenation and electrical activity after birth asphyxia: their relation to outcome. Pediatrics (2006) 117(2):333-9. doi:10.1542/peds.2005-0987

122. Shah DK, Mackay MT, Lavery S, Watson S, Harvey AS, Zempel J, et al. Accuracy of bedside electroencephalographic monitoring in comparison with simultaneous continuous conventional electroencephalography for seizure detection in term infants. Pediatrics (2008) 121(6):1146-54. doi:10.1542/peds.2007-1839

123. Evans E, Koh S, Lerner J, Sankar R, Garg M. Accuracy of amplitude integrated EEG in a neonatal cohort. Arch Dis Child Fetal Neonatal Ed (2010) 95(3):F169-73. doi:10.1136/adc.2009.165969

124. de Vries LS, Toet MC. Amplitude integrated electroencephalography in the full-term newborn. Clin Perinatol (2006) 33(3):619-32, vi. doi:10.1016/j. clp.2006.06.002

125. West CR, Harding JE, Williams CE, Nolan M, Battin MR. Cot-side electroencephalography for outcome prediction in preterm infants: observational study. Arch Dis Child Fetal Neonatal Ed (2011) 96(2):F108-13. doi:10.1136/ adc.2009.180539

126. Murphy K, Stevenson NJ, Goulding RM, Lloyd RO, Korotchikova I, Livingstone $\mathrm{V}$, et al. Automated analysis of multi-channel EEG in preterm infants. Clin Neurophysiol (2015) 126(9):1692-702. doi:10.1016/j. clinph.2014.11.024 
127. Carbine DN, Finer NN, Knodel E, Rich W. Video recording as a means of evaluating neonatal resuscitation performance. Pediatrics (2000) 106(4):654-8. doi:10.1542/peds.106.4.654

128. Thomas EJ, Sexton JB, Lasky RE, Helmreich RL, Crandell DS, Tyson J. Teamwork and quality during neonatal care in the delivery room. J Perinatol (2006) 26(3):163-9. doi:10.1038/sj.jp.7211451

129. Nadler I, Sanderson PM, Van Dyken CR, Davis PG, Liley HG. Presenting video recordings of newborn resuscitations in debriefings for teamwork training. BMJ Qual Saf (2011) 20(2):163-9. doi:10.1136/ bmjqs.2010.043547

130. McCarthy LK, Morley CJ, Davis PG, Kamlin CO, O’Donnell CP. Timing of interventions in the delivery room: does reality compare with neonatal resuscitation guidelines? J Pediatr (2013) 163(6):1553-7.e1. doi:10.1016/j. jpeds.2013.06.007

131. Fang JL, Carey WA, Lang TR, Lohse CM, Colby CE. Real-time video communication improves provider performance in a simulated neonatal resus- citation. Resuscitation (2014) 85(11):1518-22. doi:10.1016/j.resuscitation. 2014.07.019

132. O'Donnell CP, Kamlin CO, Davis PG, Morley CJ. Ethical and legal aspects of video recording neonatal resuscitation. Arch Dis Child Fetal Neonatal Ed (2008) 93(2):F82-4. doi:10.1136/adc.2007.118505

Conflict of Interest Statement: The authors declare that the research was conducted in the absence of any commercial or financial relationships that could be construed as a potential conflict of interest.

Copyright (C) 2016 Finn, Boylan, Ryan and Dempsey. This is an open-access article distributed under the terms of the Creative Commons Attribution License (CC BY). The use, distribution or reproduction in other forums is permitted, provided the original author(s) or licensor are credited and that the original publication in this journal is cited, in accordance with accepted academic practice. No use, distribution or reproduction is permitted which does not comply with these terms. 